\title{
Nucleus Reuniens Is Required for Encoding and Retrieving Precise, Hippocampal-Dependent Contextual Fear Memories in Rats
}

\author{
Karthik R. Ramanathan, Reed L. Ressler, Jingji Jin, and Stephen Maren \\ Department of Psychological and Brain Sciences and Institute for Neuroscience, Texas A\&M University, College Station, Texas 77843
}

The nucleus reuniens (RE) is a ventral midline thalamic nucleus that interconnects the medial prefrontal cortex (mPFC) and hippocampus (HPC). Considerable data indicate that HPC-mPFC circuits are involved in contextual and spatial memory; however, it is not clear whether the RE mediates the acquisition or retrieval of these memories. To examine this question, we inactivated the RE with muscimol before either the acquisition or retrieval of pavlovian fear conditioning in rats; freezing served as the index of fear. We found that RE inactivation before conditioning impaired the acquisition of contextual freezing, whereas inactivation of the RE before retrieval testing increased the generalization of freezing to a novel context; inactivation of the RE did not affect either the acquisition or expression of auditory fear conditioning. Interestingly, contextual conditioning impairments were absent when retrieval testing was also conducted after RE inactivation. Contextual memories acquired under RE inactivation were hippocampal independent, insofar as contextual freezing in rats conditioned under RE inactivation was insensitive to intrahippocampal infusions of the NMDA receptor antagonist aminophosphonovalerate. Together, these data reveal that the RE supports hippocampal-dependent encoding of precise contextual memories that allow discrimination of dangerous contexts from safe contexts. When the RE is inactive, however, alternate neural systems acquire an impoverished contextual memory that is expressed only when the RE is off-line.

Key words: context; fear conditioning; hippocampus; memory; rat; thalamus

Significance Statement

The midline thalamic nucleus reuniens (RE) coordinates communication between the hippocampus and medial prefrontal cortex, brain areas that are critical for contextual and spatial memory. Here we show that temporary pharmacological inactivation of RE impairs the acquisition and precision of contextual fear memories after pavlovian fear conditioning in rats. However, inactivating the RE before retrieval testing restored contextual memory in rats conditioned after RE inactivation. Critically, we show that imprecise contextual memories acquired under RE inactivation are learned independently of the hippocampus. These data reveal that the RE is required for hippocampal-dependent encoding of precise contextual memories to support the discrimination of safe and dangerous contexts.

\section{Introduction}

The nucleus reuniens (RE) is a ventral midline thalamic nucleus that interconnects the medial prefrontal cortex (mPFC) and hip-

\footnotetext{
Received June 5, 2018; revised Sept. 21, 2018; accepted Sept. 24, 2018.

Author contributions: K.R.R. and S.M. designed research; K.R.R., R.L.R., and J.J. performed research; K.R.R. and S.M. analyzed data; K.R.R. and S.M. wrote the paper.

This work was supported by grants from the McKnight Endowment for Neuroscience (McKnight Memory and Cognitive Disorders Award to S.M.) and the National Institutes of Health (Grants R01-MH-065961 and R01-MH117852 to S.M.). We thank Kelsey J. Clement and Sohmee Kim for technical assistance. The datasets generated during and/or analyzed during the current study are available from the corresponding author upon request.

The authors declare no competing financial interests.

Correspondence should be addressed to Stephen Maren, Department of Psychological and Brain Sciences, TAMU 4235, Texas A\&M University, College Station, TX 77843-3474. E-mail: maren@tamu.edu.

https://doi.org/10.1523/JNEUROSCl.1429-18.2018

Copyright $\odot 2018$ the authors $\quad 0270-6474 / 18 / 389925-09 \$ 15.00 / 0$
}

pocampus (HPC) and plays a critical role in both memory and emotion (McKenna and Vertes, 2004; Vertes et al., 2006; Preston and Eichenbaum, 2013; Jin and Maren, 2015a). Recent work has shown that lesions or inactivation of the RE reduces synchrony between the MPFC and HPC and produces deficits in tasks that require coordinated activity between the $\mathrm{HPC}$ and $\mathrm{mPFC}$ (Davoodi et al., 2011; Hembrook and Mair, 2011; Hembrook et al., 2012; Cholvin et al., 2013). For example, RE inactivation impairs performance in spatial working memory task that requires delayed alternation in a T-maze, and these memory deficits are accompanied by reductions in theta coherence between the mPFC and HPC (Layfield et al., 2015; Hallock et al., 2016).

Deficits in spatial working memory associated with RE inactivation may be due to deficits in contextual processing associated 
with impaired HPC-mPFC interaction (Cassel and Pereira de Vasconcelos, 2015). Consistent with this possibility, chronic inhibition of synaptic transmission in the RE made with a virally expressed tetanus toxin (TetTox) disrupts contextual processing during pavlovian fear conditioning in mice (Xu and Südhof, 2013). Specifically, permanent RE inactivation increased the generalization of fear to a novel context after contextual fear conditioning. These results suggest that the RE is involved in encoding or consolidating precise context representations that normally limit the generalization of fear from the conditioning context to other, dissimilar contexts (Vetere et al., 2017; Troyner et al., 2018).

Once learned, however, the retrieval of contextual memories does not appear to require the RE (Xu and Südhof, 2013). Yet there are considerable data in both animals and humans indicating that HPC-mPFC interactions are involved in the retrieval of spatial and contextual memories (Orsini et al., 2011; Preston and Eichenbaum, 2013; Schlichting and Preston, 2016; Wang et al., 2016; Marek et al., 2018). Indeed, recent work indicates that reversible optogenetic inhibition of the hippocampus yields deficits in both the encoding and retrieval of contextual fear memories (Goshen et al., 2011; Bernier et al., 2017). Moreover, RE inactivation produces robust impairments in spatial working memory (Griffin, 2015; Layfield et al., 2015; Hallock et al., 2016). Hence, intact acquisition and expression of contextual freezing in rats with permanent lesions of the RE (Xu and Südhof, 2013) may be due to compensation by alternate neural systems, which has been observed after hippocampal lesions, for example (Maren et al., 1997). Insofar as the RE plays a role in supporting HPC-mPFC interactions, we hypothesize that reversible inactivation of the RE will impair both the acquisition and expression of contextual fear.

To examine this question, we temporarily inactivated RE using intracranial infusions of muscimol (MUS), $\mathrm{a} \mathrm{GABA}_{\mathrm{A}}$ agonist) during either the acquisition or retrieval (or both) of pavlovian fear conditioning in rats. Retention tests were conducted in both the conditioning context and an alternate context to assess the influence of RE inactivation on context discrimination and generalization; both contextual and auditory freezing were assessed. Importantly, we included control groups in our design to determine whether state-dependent generalization deficits account for performance impairments in MUS-treated rats. Consistent with our hypothesis, we found that the RE is involved in both the encoding and retrieval of context representations that support contextual discrimination. Interestingly, deficits in contextual freezing after fear conditioning under RE inactivation could be rescued by inactivating the RE during retrieval testing. However, the contextual memories acquired under RE inactivation were hippocampal independent, insofar as contextual freezing in rats conditioned under RE inactivation was insensitive to intrahippocampal infusions of aminophosphonovalerate(APV). This supports the view that the RE is a component of a hippocampal memory system that prioritizes the encoding of a configural representation of context that ultimately overshadows its underlying elements.

\section{Materials and Methods}

\section{Subjects}

One hundred seventy experimentally naive adult male Long-Evans rats (weight, 200-224 g; age, 50-57 d old; Blue Spruce Farms; RRID: RGD_5508398) were obtained from a commercial supplier (Envigo). The rats were individually housed in cages within a temperature- and humidity-controlled vivarium and kept on a 14/10 h light/dark cycle (lights on at 07:00 h) with ad libitum access to food and water. All experiments took place during the light phase of the cycle. Rats were handled for $1 \mathrm{~min} / \mathrm{d}$ for $5 \mathrm{~d}$ to habituate them to the experimenter before they underwent surgery. All experiments were conducted at Texas A\&M University with approval from its Animal Care and Use Committee.

\section{Surgical procedures}

One week before behavioral testing, rats were anesthetized with isoflurane (5\% for induction, $\sim 2 \%$ for maintenance) and placed into a stereotaxic instrument (Kopf Instruments). An incision was made in the scalp, and the head was leveled by placing bregma and lambda in the same horizontal plane. Small holes were drilled into the skull to affix three jeweler's screws and to allow the implantation of guide cannulas (coordinates relative to bregma) targeting either RE or dorsal HPC (DH). For Experiment 1, RE was targeted using a single guide cannula $(8 \mathrm{~mm}, 26$ gauge; Plastics One) implanted at a $10^{\circ}$ angle on the midline (anteroposterior (AP), $-2.0 \mathrm{~mm}$; mediolateral (ML), $-1.0 \mathrm{~mm}$; dorsoventral (DV), $-6.7 \mathrm{~mm}$ from dura]. For Experiment 2, three guide cannulas were implanted to target RE (single midline) and DH (bilateral) in the same animal. The $\mathrm{DH}$ was targeted using two guide cannulas ( $4 \mathrm{~mm}$, 26 gauge; Plastics One) implanted at a $20^{\circ}$ angle (AP, $-3.7 \mathrm{~mm}$; ML, $\pm 3.5 \mathrm{~mm}$; $\mathrm{DV},-3.2 \mathrm{~mm}$ from dura). The guide cannulas were affixed to the skull with dental cement, and stainless steel dummy cannulas (31 gauge, $9 \mathrm{~mm}$ for the RE and $5 \mathrm{~mm}$ for the $\mathrm{DH}$; Plastics One) were inserted into the guides. Rats were allowed to recover for $7 \mathrm{~d}$ after surgery before behavioral testing; dummy cannulas were replaced twice during this period.

\section{Drug infusions}

For intracranial microinfusions, rats were transported to the laboratory in 5 gallon white buckets filled with a layer of bedding. The dummies were removed, and stainless steel injectors ( 31 gauge; $9 \mathrm{~mm}$ for RE; $5 \mathrm{~mm}$ for $\mathrm{DH}$ ) connected to polyethylene (PE) tubing were inserted into the guide cannulas for intracranial infusions. The PE tubing on each injector was connected to a Hamilton syringe $(10 \mu \mathrm{l})$, which was mounted on an infusion pump (KD Scientific). Infusions were monitored by the movement of an air bubble that separated the drug or saline (SAL) solutions from distilled water within the PE tubing. All infusions were made $\sim 10$ min before either the conditioning or retrieval test sessions. MUS (0.1 $\mu \mathrm{g} / \mu \mathrm{l})$ and APV $(10 \mu \mathrm{g} / \mu \mathrm{l})$ were dissolved in sterile SAL and infused at a rate of $0.1 \mu \mathrm{l} / \mathrm{min}$ for $3 \mathrm{~min}(0.3 \mu \mathrm{l}$ total; $0.03 \mu \mathrm{g}$ MUS in RE; $3 \mu \mathrm{g}$ APV per hemisphere in DH); the injectors were left in place for 2-3 min for diffusion. After the infusions, clean dummies were inserted into the guide cannulas and the animals were transported to the conditioning chambers for the behavioral sessions.

\section{Behavioral apparatus}

Sixteen identical rodent conditioning chambers $(30 \times 24 \times 21 \mathrm{~cm}$; Med Associates) housed in sound-attenuating cabinets were used in all behavioral sessions. Each chamber consisted of two aluminum sidewalls, a Plexiglas ceiling and rear wall, and a hinged Plexiglas door. The floor consisted of 19 stainless steel rods that were wired to a shock source and a solid-state grid scrambler (Med Associates) for the delivery of footshock. A speaker mounted outside the grating of one aluminum wall was used to deliver auditory stimuli. Additionally, ventilation fans in the cabinets and a house light in each chamber were used to create distinct contexts. Each conditioning chamber rested on a load-cell platform that was used to record chamber displacement in response to the motor activity of each rat. Load-cell voltages were digitized and recorded on a computer using threshold activity software (Med Associates). For each chamber, load-cell voltages are digitized at $5 \mathrm{~Hz}$, yielding one observation every $200 \mathrm{~ms}$. Freezing was quantified by computing the number of observations for each rat that had a value less than the freezing threshold (load-cell activity $=10)$. Freezing was scored only if the rat is immobile for at least $1 \mathrm{~s}$. Environmental stimuli were manipulated within two different laboratory rooms housing the conditioning chambers (eight chambers/room) to generate two distinct contexts. For context A, a $15 \mathrm{~W}$ house light within each chamber was turned on and the overhead fluorescent room lights remained on. Ventilation fans $(65 \mathrm{~dB})$ were turned on, cabinet doors were left open, and the chambers were cleaned with $1 \%$ ammonium hydroxide. Rats were transported to context A in white plas- 

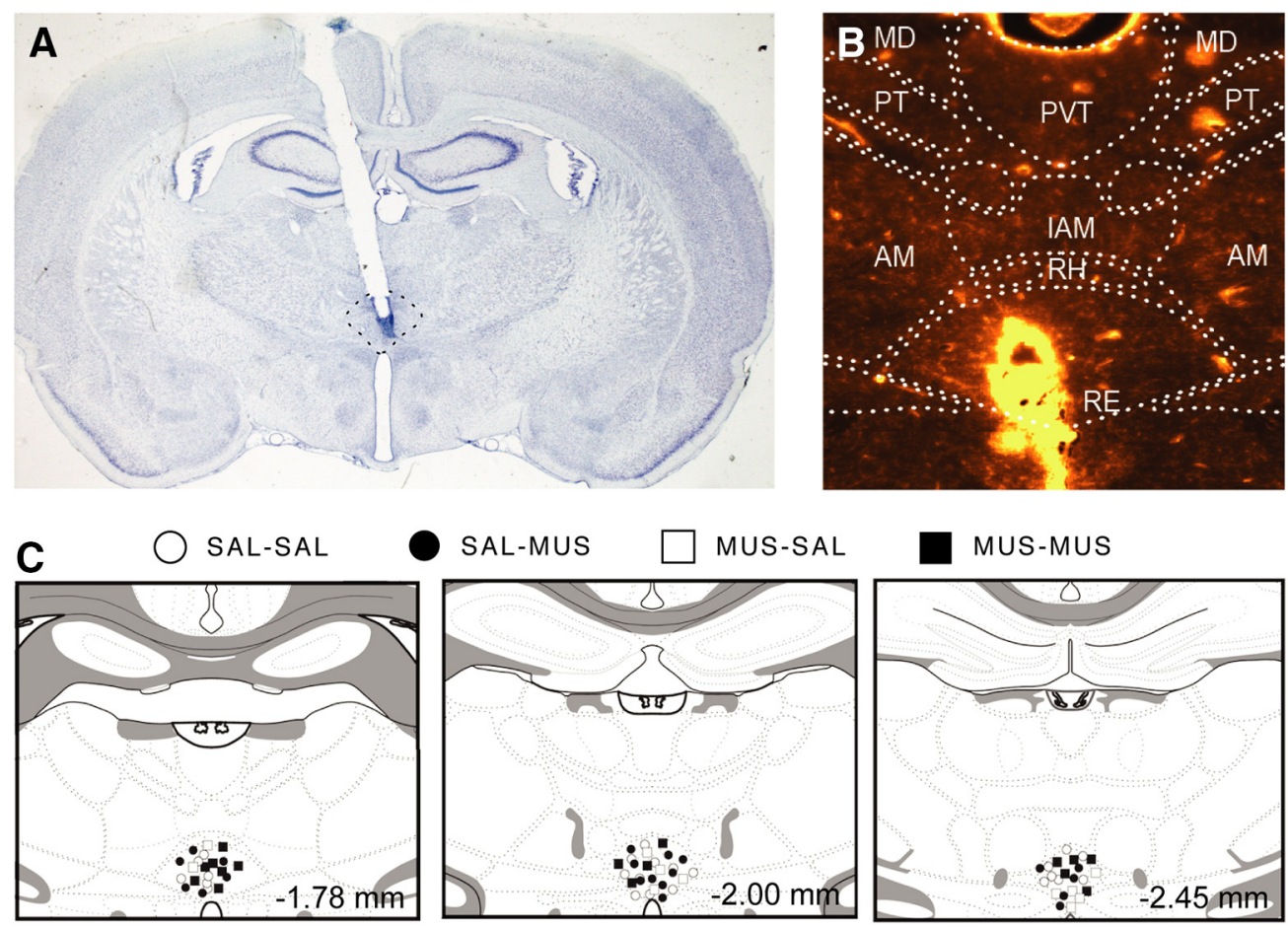

Figure 1. Cannula placements in the RE. $A$, Representative thionin-stained coronal section showing a midline cannula placement in the RE. $\boldsymbol{B}$, Representative dark-field image showing diffusion of fluorescent muscimol $(0.3 \mu \mathrm{l}$; TMR-X) in the RE. C, Cannula placements for all subjects that were included in the analysis across three different levels along the anterior-posterior axis. The distribution of cannula placements within the RE was similar across all of the groups. MD, Medial dorsal nucleus; PT, paratenial thalamus; PVT, paraventricular nucleus of the thalamus; AM, anteromedial; IAM, Interaanteromedial nucleus; RH, Rhomboid nucleus.

tic boxes. For context B, the house lights were turned off and an overhead red fluorescent room light was turned on. The cabinet doors were closed, and the chambers were cleaned with $1.5 \%$ acetic acid. Rats were transported to context B in black plastic boxes.

\section{Behavioral procedures}

Experiment 1. The experiment was run in two replications with half of the animals undergoing a contextual conditioning fear procedure $(n=64)$ and the other half undergoing an auditory fear conditioning procedure $(n=64)$. There were no statistical differences (all $F$ values $<1.2 ; p>0.3$ ) across these replications in the effects of RE inactivation on the acquisition or expression of freezing during conditioning or the context retrieval tests, so the data from these sessions were collapsed. Conditioned freezing to the tone conditioned stimulus (CS) was assessed only in the cohort that underwent auditory fear conditioning.

Approximately 1 week after surgery, the animals were randomly assigned to one of the following four groups: SAL-SAL, SAL-MUS, MUSSAL, and MUS-MUS. On day 1, rats received microinfusions of either MUS or SAL and were subjected to either contextual or auditory fear conditioning in context A. The conditioning session consisted of a 3 min baseline followed by unconditioned stimuli (USs) consisting of five footshocks ( $1 \mathrm{~mA}, 2 \mathrm{~s})$ separated by $70 \mathrm{~s}$ intertrial intervals (ITIs). In half of the animals, the US was preceded by a $10 \mathrm{~s}$ auditory CS $(2 \mathrm{kHz}, 80 \mathrm{~dB})$. Twenty-four hours later, rats again received microinfusions of MUS or SAL and were placed in either the conditioning context (A) or a novel context (B) for a $10 \mathrm{~min}$ stimulus-free retrieval test to assess conditioned freezing and its generalization, respectively. Each rat was tested in each context in a counterbalanced fashion across $2 \mathrm{~d}$, and the infusion group assignment was the same for each test. Rats that received auditory fear conditioning were tested identically, except that five CS-alone test trials (30 s ISIs) were delivered after the $10 \mathrm{~min}$ baseline (generalization test) period in context $\mathrm{B}$.

Experiment 2. This experiment was run in two replications. After recovery from surgery, animals were assigned to one of the following four groups: $\mathrm{DH}_{\mathrm{SAL}}-\mathrm{RE}_{\mathrm{SAL}}, \mathrm{DH}_{\mathrm{SAL}}-\mathrm{RE}_{\mathrm{MUS}}, \mathrm{DH}_{\mathrm{APV}}-\mathrm{RE}_{\mathrm{SAL}}$, and $\mathrm{DH}_{\mathrm{APV}}-$ $\mathrm{RE}_{\mathrm{MUS}}$. Animals received either SAL or APV infusions into the $\mathrm{DH}$ and either SAL or MUS into the RE before conditioning; all animals were then tested after an infusion of SAL or MUS into the RE (the RE drug infusion during testing was the same as that during conditioning). This design permitted us to determine whether contextual conditioning under RE inactivation requires NMDA receptors in the DH. After DH and RE infusions on day 1 , the conditioning session consisted of a 3 min baseline followed by 5 footshock USs ( $1 \mathrm{~mA}, 2 \mathrm{~s})$ separated by $70 \mathrm{~s}$ ITIs. Fortyeight hours after conditioning, rats again received microinfusions of MUS or SAL in RE and were placed in the conditioning context (A) for a 10 min stimulus-free retrieval test to assess contextual freezing.

\section{Histological procedures}

Upon completion of the experiment, rats were overdosed with sodium pentobarbital (100 mg/kg; Fatal Plus) and perfused transcardially with $0.9 \%$ saline followed by $10 \%$ formalin. The brains were extracted from the skull and postfixed in a $10 \%$ formalin solution for $24 \mathrm{~h}$ followed by a $30 \%$ sucrose-formalin solution where they remained for a minimum of $72 \mathrm{~h}$. After the brains were fixed, coronal sections ( $40 \mu \mathrm{m}$ thickness) were made on a cryostat $\left(-20^{\circ} \mathrm{C}\right)$, mounted on subbed microscope slides, and stained with thionin $(0.25 \%)$ to visualize cannula placements (Fig. $1 \mathrm{~A}$, representative cannula placement).

\section{Experimental design and statistical analysis}

In Experiment 1 , rats $(n=128)$ were randomly assigned to a $2 \times 2$ factorial design with variables of drug condition (SAL or MUS infusions into RE) before fear conditioning and/or retrieval testing. This design resulted in the following four experimental groups: SAL-SAL, SAL-MUS, MUS-SAL, and MUS-MUS. Half of the animals underwent contextual fear conditioning ( $n=64 ; n=16 /$ group), and the other half underwent auditory fear conditioning ( $n=64 ; n=16$ /group). Ultimately, the contextual freezing data were collapsed across these experiments, resulting in 32 subjects/group. During the course of the experiment, three rats died or were killed before completion of the experiment and were excluded from the analysis. Of the remaining animals, 14 were excluded due to poor cannula placements, resulting in the following final group sizes for the conditioning session and context retrieval tests: SAL-SAL, $n=29$; SAL- 
A

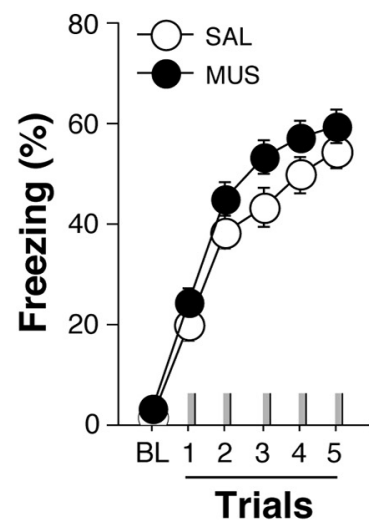

B

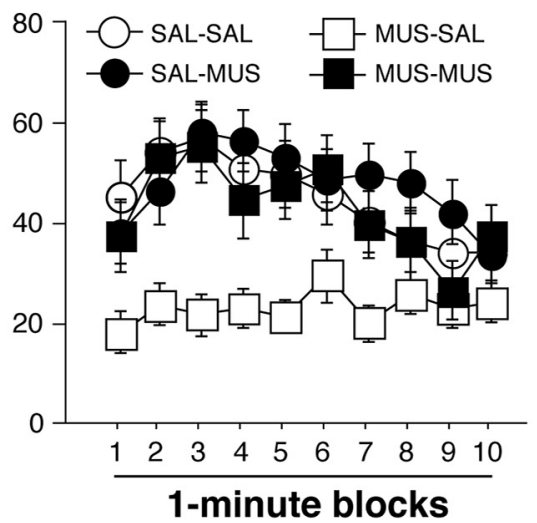

C

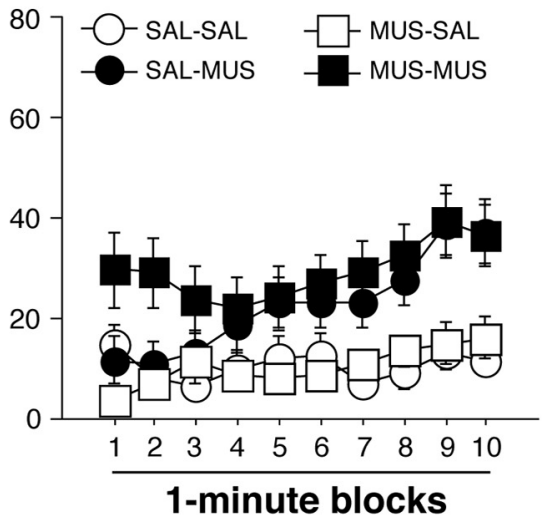

Figure 2. Muscimol inactivation of the RE results in a state-dependent impairment in contextual fear conditioning. $\boldsymbol{A}$, Percentage of freezing during the 3 min baseline (BL) and 1 min ITI after each conditioning trial (indicated by gray hatch marks on the $x$-axis) in animals infused with either SAL or MUS in the RE. $B$, Percentage of freezing during the 10 min retrieval test in the conditioning context. Animals conditioned after SAL or MUS infusions received the retrieval test after either SAL or MUS infusions in a factorial design that yielded the following four groups: SAL-SAL, MUS-SAL, SAL-MUS, and MUS-MUS. C, Percentage of freezing during the 10 min retrieval test in a novel context (the order of the retrieval tests in context $A$ and $B$ was counterbalanced); the groups are the same as those described in $B$. All data are shown as the mean \pm SEM.

MUS, $n=27$; MUS-SAL, $n=31$; MUS-MUS, $n=24$. Freezing to the tone was assessed in approximately half the number of subjects, as follows: SAL-SAL, $n=16$; SAL-MUS, $n=13$; MUS-SAL, $n=16$; MUSMUS, $n=11$.

In Experiment 2, rats $(n=42)$ were assigned to a $2 \times 2$ factorial design with variables of $\mathrm{DH}$ drug condition before fear conditioning (SAL or APV) and RE drug condition before conditioning and retrieval testing (SAL-SAL or MUS-MUS). This design resulted in the following four experimental groups: $\mathrm{DH}_{\mathrm{SAL}}-\mathrm{RE}_{\mathrm{SAL}}(n=9) ; \mathrm{DH}_{\mathrm{APV}}-\mathrm{RE}_{\mathrm{SAL}}(n=13)$; $\mathrm{DH}_{\mathrm{SAL}}-\mathrm{RE}_{\mathrm{MUS}}(n=8)$; and $\mathrm{DH}_{\mathrm{APV}}-\mathrm{RE}_{\mathrm{MUS}}(n=12)$. Two rats died or were killed before completion of the experiment; of the remaining 40 animals, 8 were excluded due to poor cannula placements or inadvertent lesions associated with cannula placement or drug infusions. One animal that exhibited average freezing that was $>2$ SDs above its group mean was excluded, resulting in the following final group sizes: $\mathrm{DH}_{\mathrm{SAL}}-\mathrm{RE}_{\mathrm{SAL}}$, $n=9 ; \mathrm{DH}_{\mathrm{APV}}-\mathrm{RE}_{\mathrm{SAL}}, n=9 ; \mathrm{DH}_{\mathrm{SAL}}-\mathrm{RE}_{\mathrm{MUS}}, n=7$; and $\mathrm{DH}_{\mathrm{APV}}-\mathrm{RE}_{\mathrm{MUS}}$, $n=7$.

All behavioral data (mean \pm SEM) are represented by the average percentage of freezing behavior during $1 \mathrm{~min}$ intervals during the conditioning session and retrieval tests. For those animals undergoing a tone retrieval test, freezing was averaged across both the auditory CS and the subsequent $30 \mathrm{~s}$ ISI (CS + ITI). Freezing during the CS + ITI period is highly correlated with freezing to the CS itself and is less susceptible to competition by active CS-elicited orienting responses. For the conditioning and retrieval test sessions, the behavioral data were analyzed with a three-way mixed-model ANOVA with between-subject factors of drug condition during conditioning and testing and within-subject factors test minute. Analyses of contextual discrimination performance consisted of a two-way mixed-model ANOVA with a between-subject factor of drug condition during conditioning and testing and a within-subject factor of test context [conditioning (A) or novel (B)]. Last, the discrimination ratio and auditory freezing data in Experiment 1 and contextual test performance in Experiment 2 were the freezing data that were averaged across the test minutes, and these data were analyzed with two-way ANOVAs with between-subject factors of drug condition during conditioning and retrieval testing. Post hoc comparisons in the form of Fisher's protected least significant difference tests were performed after a significant overall $F$ ratio in the ANOVA ( $\alpha=0.05$ for both main effects and interactions). A sample size of eight rats per group is sufficient to detect the effect sizes anticipated in the present experiments ( $\mathrm{G}^{\star}$ Power), and the final group sizes in each experiment resulted from two independent replications. Statistical analyses were performed with StatView version 5.0.1 (SAS Institute) running under an open-source PowerPC Apple MacOS emulator (SheepShaver; https://sheepshaver.cebix.net).

\section{Results}

Inactivation of RE impairs acquisition of contextual conditioning and generalization of conditioned freezing

Figure 1, $A$ and $B$, illustrates Representative thionin stained sections and spread of fluorescently labeled muscimol (TMR-X) in the RE along with an illustration of cannula placements in all the animals included in the analyses (Fig. 1C). During the fearconditioning session, rats receiving SAL or MUS infusions into the RE exhibited low levels of freezing behavior before the first conditioning trial and increased their freezing behavior across the conditioning trials (Fig. 2A); there were no differences between MUS- and SAL-treated rats in the levels of conditioned freezing. These observations were confirmed in a one-way repeatedmeasures ANOVA that revealed a significant main effect of training trial $\left(F_{(5,545)}=166.9 ; p<0.0001\right)$ with neither a main effect of drug $\left(F_{(1,109)}=3.56 ; p=0.06\right)$ nor a drug $\times$ trial interaction $\left(F_{(5,545)}=0.78 ; p=0.57\right)$. Hence, RE inactivation did not affect the expression of postshock freezing during the acquisition of pavlovian fear conditioning.

Twenty-four and forty-eight hours later, all animals were again infused with either SAL or MUS and placed in either the conditioning context (A) or a novel context (B) for a $10 \mathrm{~min}$ retrieval test; the test order in the two contexts was counterbalanced, and the infusion assignment for each test was the same. Importantly, this design allowed us to assess the state-dependent effects of RE inactivation on the acquisition, expression, and generalization of conditioned freezing. As shown in Figure $2 B$, rats conditioned after MUS infusions into the RE (MUS-SAL group) exhibited a substantial impairment in conditioned freezing in the conditioning context. Interestingly, this impairment was absent in animals both conditioned and tested after MUS infusions into the RE (MUS-MUS group). The relatively high level of freezing behavior in the MUS-MUS rats was not simply due to a nonspecific increase in freezing caused by RE inactivation insofar as SAL-MUS animals were no different from SAL-SAL or MUSMUS animals. All of these observations were confirmed in a twoway repeated-measures ANOVA that revealed significant main effects for conditioning drug $\left(F_{(1,107)}=8.28 ; p=0.004\right)$, testing $\operatorname{drug}\left(F_{(1,107)}=6.04 ; p=0.02\right)$, and time $\left(F_{(1,107)}=8.90 ; p<\right.$ 
0.0001). Moreover, there was a trend toward a significant interaction between conditioning and testing drug conditions $\left(F_{(1,107)}\right.$ $=3.52 ; p=0.06$; Fig. 2B). Post hoc comparisons revealed that freezing among rats in the MUS-SAL group was significantly lower than that in the SAL-SAL $(p=0.0007)$, SAL-MUS ( $p=$ 0.0002 ), and MUS-MUS ( $p=0.003$ ) groups, which did not differ from one another. This reveals that RE inactivation impairs the acquisition of contextual fear conditioning and does so in a statedependent manner; testing animals in the same state under which they were conditioned resulted in high levels of conditioned freezing.

In contrast, when the animals were tested for their generalization of fear to a novel context, a different pattern of results emerged. As shown in Figure 2C, rats conditioned after MUS inactivation of the RE exhibited similar and low levels of freezing relative to animals conditioned under SAL. However, MUS infusions before the generalization test increased conditioned freezing. Interestingly, animals conditioned and tested under MUS (MUS-MUS) exhibited the highest level of freezing, and this was manifest early in the test session. Rats conditioned under SAL and tested under MUS (SAL-MUS) showed low levels of freezing at the beginning of the test that increased over the course of the test to approach those in the MUS-MUS group. These observations were confirmed in a two-way repeated-measures ANOVA that revealed a significant main effect of test drug $\left(F_{(1,107)}=22.78\right.$; $p<0.0001)$ and time $\left(F_{(9,963)}=7.65 ; p<0.0001\right)$; there was no interaction between conditioning and test drug $\left(F_{(1,107)}=1.1\right.$; $p=0.29)$. However, there was a significant interaction between test drug and time $\left(F_{(9,963)}=2.31 ; p=0.014\right)$, which indicates that MUS increased the generalization of fear (SAL-MUS), and served as a retrieval cue to support contextual freezing in rats conditioned after MUS infusions in the RE (MUS-MUS). Importantly, increases in freezing were not due to nonspecific effects of MUS on locomotion, insofar as MUS did not decrease locomotor (i.e., load-cell) activity during the pretrial baseline period on the conditioning day or affect shock-elicited activity (data not shown).

\section{RE inactivation impairs contextual discrimination}

Because animals received the same drug infusions across both of the context tests, we were able to assess contextual discrimination using a within-subjects analysis. As shown in Figure $3 A$, rats in all of the groups exhibited contextual discrimination and exhibited lower levels of freezing in context B compared with context A. Consistent with this observation, a three-way repeated-measures ANOVA with between-subject variables of conditioning and testing drug condition and a within-subject variable of test context revealed a significant main effect of test context $\left(F_{(1,107)}=80.48\right.$; $p<0.0001)$. Furthermore, there was a significant main effect of test drug $\left(F_{(1,107)}=17.42 ; p<0.0001\right)$, but not of conditioning $\operatorname{drug}\left(F_{(1,107)}=2.3 ; p=0.13\right)$, although there was a trend toward a significant interaction between the drug conditions $\left(F_{(1,107)}=\right.$ $3.48 ; p=0.06)$. Close examination of these data reveals that the SAL-SAL animals exhibited the highest level of contextual discrimination relative to all the other groups. To examine this possibility more closely, we calculated a discrimination index by computing the ratio between the differences in the average freezing across the 10 min tests (context $\mathrm{A}-$ context $\mathrm{B}$ ) divided by the total freezing in each context (context A + context B). As shown in Figure 3B, MUS infusions into RE resulted in lower discrimination scores, whether the infusions occurred before conditioning or retrieval testing. A factorial ANOVA revealed a trend toward a significant main effect of conditioning drug $\left(F_{(1,107)}=\right.$
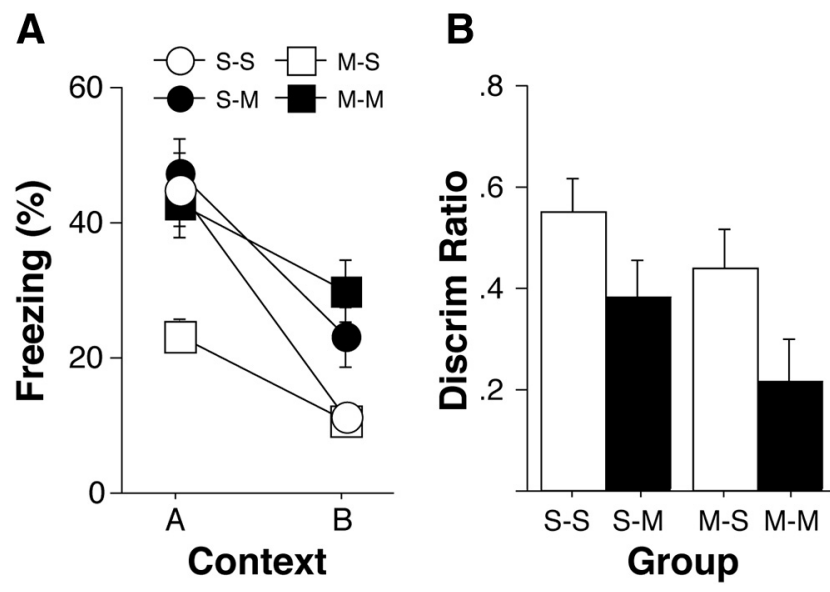

Figure 3. Muscimol inactivation of the RE impairs contextual discrimination. $A$, Average percentage of freezing across the 10 min retrieval tests in the context $A$ and context $B$ shown in Figure 2. The order of the two retrieval tests was counterbalanced and animals trained under saline (S) or muscimol (M) were tested in both contexts $A$ and $B$ after either saline or muscimol infusions to yield the four groups described in Figure 2 (e.g., S-S, S-M, M-S, and M-M). $\boldsymbol{B}$, Average discrimination ratios [(context A - context B)/(context A + context B)] calculated on freezing behavior across the $10 \mathrm{~min}$ tests shown in $A$. All data are shown as the mean \pm SEM.

\section{A}

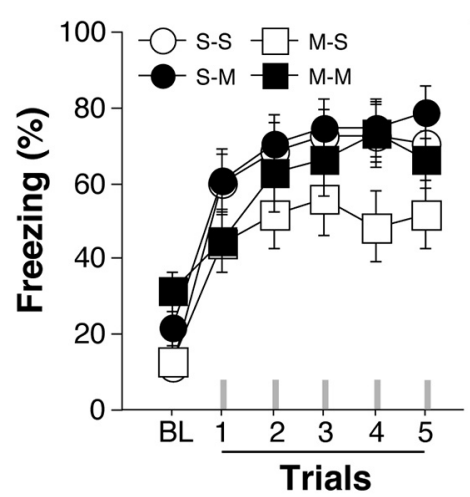

B

Figure 4. Muscimol inactivation of RE did not impair the acquisition or expression of freezing to an auditory CS. A, Average percentage of freezing during a 10 min stimulus free baseline (BL) and after five tone presentations (indicated by the gray hatch marks on the $x$-axis) during an auditory retrieval test. Freezing during each trial represents the average freezing during the $C S$ and ITI. Animals received either saline $(S)$ or muscimol $(M)$ infusions before conditioning and retrieval testing in a factorial design to yield four groups (S-S, M-S, S-M, M-M). B, Average percentage of freezing across all five $C S$ trials shown in $A$. All data are shown as the mean \pm SEM.

$3.62 ; p=0.06)$ and a significant main effect of drug during testing $\left(F_{(1,107)}=6.83 ; p=0.01\right)$; there was no significant interaction between these factors $\left(F_{(1,107)}=0.16 ; p=0.69\right)$. Hence, it appears that RE inactivation reduces contextual discrimination when infused either before conditioning or retrieval testing.

\section{RE inactivation does not impair acquisition or expression of freezing to an auditory CS}

Of the subset of animals that received auditory fear conditioning, we determined whether the inactivation of RE causes deficits in the acquisition or expression of fear to the tone CS. As shown in Figure $4 A$ and $B$, conditional freezing to the tone was similar in all of the groups. Two-way repeated-measures ANOVA revealed no significant main effects or interactions of drug on conditioning $\left(F_{(1,52)}=2.6 ; p=0.12\right)$ or testing $\left(F_{(1,52)}=1.77 ; p=0.19\right)$ across 
A

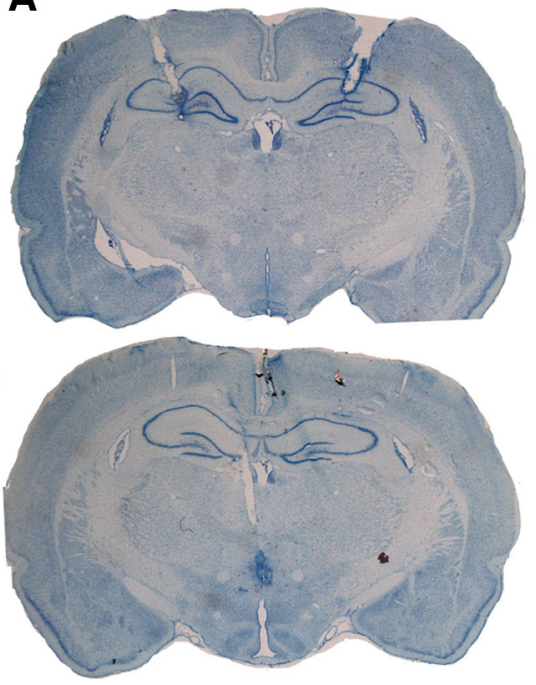

B
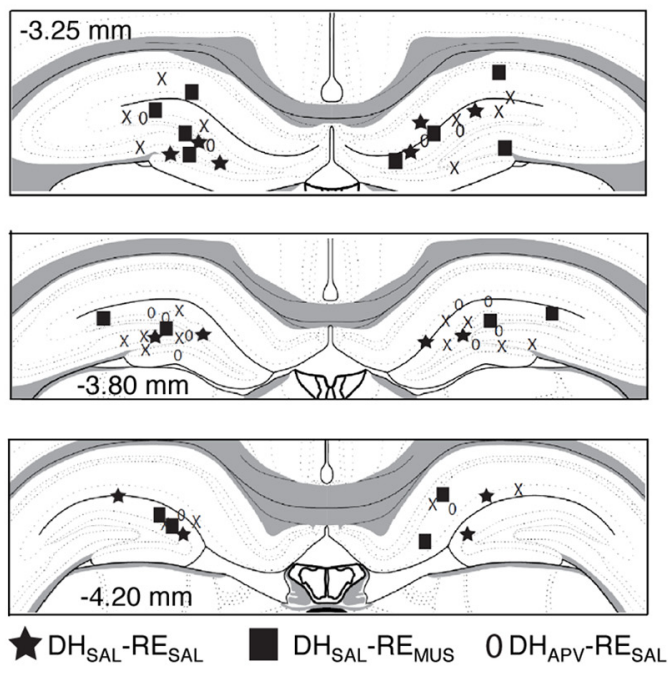
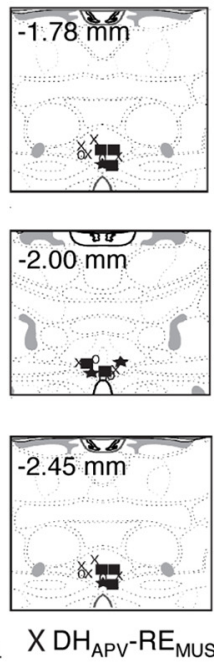

Figure 5. Cannula placements in the RE and DH. $\boldsymbol{A}$, Representative thionin-stained coronal sections showing a midline cannula placement in the RE (left) and DH (right). $\boldsymbol{B}$, Cannula placements for all subjects that were included in the analysis across three different levels along the anterior-posterior axis in both DH (top) and RE (bottom). The distribution of cannula placements within the RE and DH was similar across all of the groups.

the entire test. Moreover, average freezing during the CS trials (Fig. 4B) did not differ between the groups (conditioning: $F_{(1,52)}=3.47, p=0.07$; testing: $F_{(1,52)}=$ $1.05, p=0.31)$. Overall, these results indicate that inactivation of RE does not cause deficits in either the acquisition or retrieval of fear to an auditory CS.

Contextual memories acquired under RE inactivation are insensitive to hippocampal NMDA receptor antagonism Animals conditioned and tested under RE inactivation exhibited high levels of freezing in the conditioning context, suggesting that they had acquired a contextual memory. Because considerable evidence indicates that RE inactivation impairs hippocampal-dependent memory encoding (Layfield et al., 2015; Hallock et al., 2016), contextual learning in rats conditioned under RE inactivation may not require hippocampal synaptic plasticity (Stiedl et al., 2000; Quinn et al., 2005; Czerniawski et al., 2012). To test this possibility, we examined whether intra-

hippocampal infusions of the NMDA receptor antagonist APV impair contextual conditioning when training occurs under simultaneous RE inactivation.

Representative cannula placements in $\mathrm{RE}$ or $\mathrm{DH}$ along with an illustration of cannula placements in all of the animals included in the analyses are shown in Figure 5. During fear conditioning, all rats exhibited low levels of freezing behavior before the first conditioning trial and increased their freezing behavior across the conditioning trials (Fig. 6A). There were no differences between the groups in the levels of conditioned freezing. A one-way repeated-measures ANOVA revealed a significant main effect of conditioning trial $\left(F_{(5,140)}=32.79 ; p<0.0001\right)$ with neither a
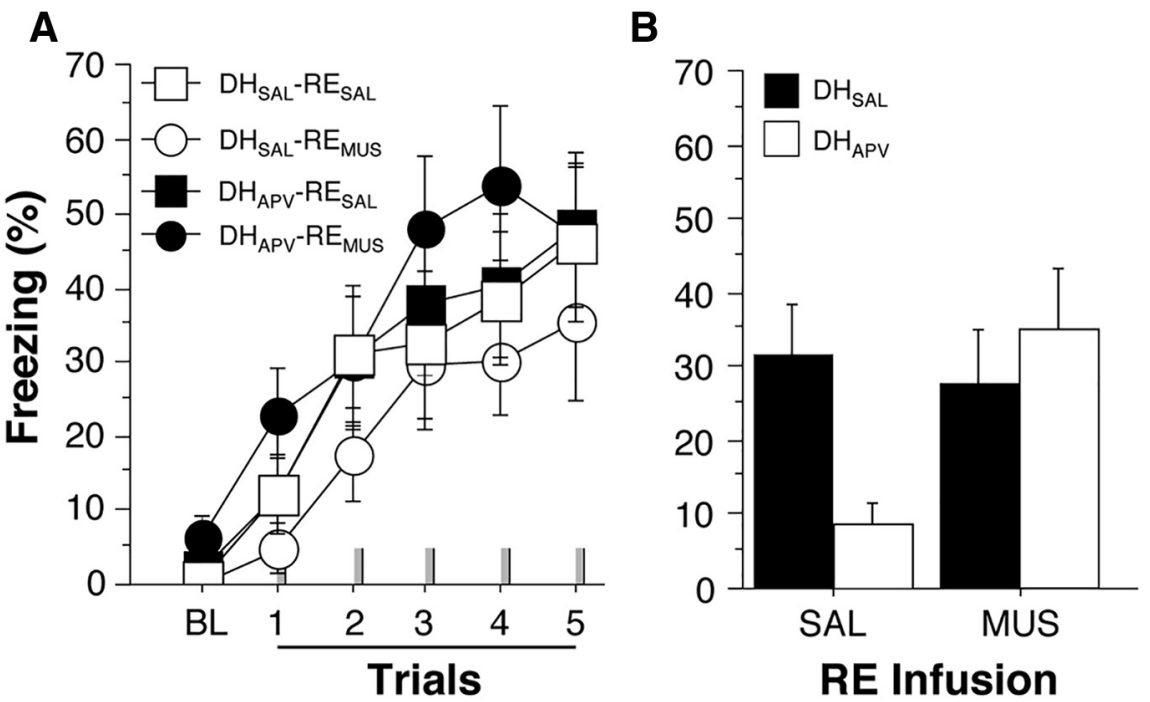

Figure 6. Contextual conditioning under RE inactivation is insensitive to NMDA receptor antagonism in the DH. $\boldsymbol{A}$, Percentage of freezing during the 3 min baseline (BL) and 1 min ITI after each conditioning trial (indicated by gray hatch marks on the $x$-axis) in animals infused with either SAL or MUS in the RE and APV or SAL infused in DH. $B$, Percentage of freezing during the 10 min retrieval test in the conditioning context. Animals conditioned after SAL or MUS infusions in RE received the same drug infusions in

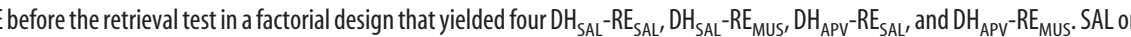
APV indicates drug infusions in DH before fear conditioning, and SAL or MUS indicate the RE infusions before both conditioning and the retrieval test. All data are shown as the mean \pm SEM.

main effect of drug in $\operatorname{RE}\left(F_{(1,28)}=0.005 ; p=0.94\right)$ and drug in $\mathrm{DH}\left(F_{(1,28)}=1.81 ; p=0.19\right)$ nor a drug $\times$ trial interaction $\left(F_{(1,28)}=1.17 ; p=0.29\right)$. Hence, neither MUS infusions into RE nor APV infusions into $\mathrm{DH}$ affected postshock freezing during the acquisition of pavlovian fear conditioning.

Forty-eight hours later, all animals were again infused with either SAL or MUS in RE and placed in the conditioning context (A) for a 10 min retrieval test (the drug infused before retrieval testing was identical to that infused before conditioning); there were no DH infusions before a retrieval test. As shown in Figure $6 B$, rats conditioned after APV infusions into the $\mathrm{DH}$ and SAL infusions into the RE $\left(\mathrm{DH}_{\mathrm{APV}}-\mathrm{RE}_{\mathrm{SAL}}\right)$ exhibited a substantial im- 
pairment in conditioned freezing in the conditioning context relative to animals receiving SAL infusions into both $\mathrm{DH}$ and $\mathrm{RE}$ $\left(\mathrm{DH}_{\mathrm{SAL}}-\mathrm{RE}_{\mathrm{SAL}}\right)$. Interestingly, this impairment was absent in animals that received MUS infusions to $\mathrm{RE}\left(\mathrm{DH}_{\mathrm{APV}}-\mathrm{RE}_{\mathrm{MUS}}\right)$ who froze at levels similar to those in controls $\left(\mathrm{DH}_{\mathrm{SAL}}-\mathrm{RE}_{\mathrm{SAL}}\right.$ and $\left.\mathrm{DH}_{\mathrm{SAL}}-\mathrm{RE}_{\mathrm{MUS}}\right)$. The relatively high level of freezing behavior in the $\mathrm{DH}_{\mathrm{APV}}-\mathrm{RE}_{\mathrm{MUS}}$ animals was not simply due to a nonspecific increase in freezing caused by drug infusions in RE insofar as the level of freezing in $\mathrm{DH}_{\mathrm{APV}}-\mathrm{RE}_{\mathrm{MUS}}$ group was similar to that in animals conditioned under $\mathrm{RE}$ inactivation alone $\left(\mathrm{DH}_{\mathrm{SAL}^{-}}\right.$ $\left.\mathrm{RE}_{\mathrm{MUS}}\right)$ and SAL controls $\left(\mathrm{DH}_{\mathrm{SAL}}-\mathrm{RE}_{\mathrm{SAL}}\right)$. These observations were confirmed in a two-way repeated-measures ANOVA that revealed a significant interaction between RE and DH drug conditions $\left(F_{(1,28)}=5.91 ; p=0.02\right)$; there was no main effect of $\mathrm{RE}$ drug condition $\left(F_{(1,28)}=3.11 ; p=0.09\right)$ or DH drug condition $\left(F_{(1,28)}=1.52 ; p=0.23\right)$. Post hoc comparisons revealed that freezing among rats in the $\mathrm{DH}_{\mathrm{APV}}-\mathrm{RE}_{\mathrm{SAL}}$ group was significantly lower than that in the $\mathrm{DH}_{\mathrm{SAL}}-\mathrm{RE}_{\mathrm{SAL}}(p=0.0098), \mathrm{DH}_{\mathrm{SAL}}-\mathrm{RE}_{\mathrm{MUS}}$ $(p=0.0432)$, and $\mathrm{DH}_{\mathrm{APV}}-\mathrm{RE}_{\mathrm{MUS}}(p=0.0061)$ groups, which did not differ from one another. This reveals that although contextual conditioning normally requires hippocampal NMDA receptors, contextual memories acquired after inactivation of the RE do not require DH NMDA receptors.

\section{Discussion}

The present study examined the role of the RE in the acquisition, expression, and generalization of conditioned freezing in rats. Inactivation of RE before fear conditioning impaired contextual freezing in the conditioning context. Importantly, this deficit could be completely rescued by testing animals under RE inactivation, indicating that the contextual memory acquired under RE inactivation can be expressed, but only when the RE is off-line. Memories acquired or expressed under RE inactivation were less precise, insofar as RE inactivation increased the generalization of contextual fear to a novel context. Last, contextual memories acquired under RE inactivation were not impaired by NMDA receptor antagonism in the $\mathrm{DH}$, revealing that nonhippocampal systems acquire contextual memory in the absence of the RE. Collectively, these data reveal that the RE is required for hippocampal-dependent encoding of precise contextual memories to support the discrimination of safe and dangerous contexts.

The discovery that RE inactivation impairs the acquisition of precise context memories is consistent with prior work showing that TetTox inhibition of synaptic inputs to the RE, particularly from the PFC, leads to increased generalization of contextual fear without affecting fear to an auditory CS (Xu and Südhof, 2013). The specific role for RE in processing contextual, as opposed to discrete CSs is consistent with previous work from our laboratory showing that HPC-PFC interactions are involved in contextual regulation of fear memories, rather than CS freezing per se (Jin and Maren, 2015a,b; Wang et al., 2016; Marek et al., 2018). In contrast to the present results, Xu and Südhof (2013) did not observe deficits in the acquisition of contextual freezing after RE inactivation. However, as we have shown here, memories encoded under RE inactivation can be retrieved when the RE is off-line. Irreversible inhibition of synaptic function in RE would allow hippocampal-independent memories of context to be encoded and expressed.

Unexpectedly, inactivating the RE before retrieval testing did not impair freezing in the conditioning context in animals that were conditioned intact. Previous work has shown that RE inactivation impairs memory retrieval in a variety of tasks (Hem- brook and Mair, 2011; Hembrook et al., 2012; Cholvin et al., 2013; Jin and Maren, 2015a; Layfield et al., 2015), presumably by disrupting mPFC-HPC synchrony (Preston and Eichenbaum, 2013; Griffin, 2015; Jin and Maren, 2015a). However, as we have observed in the present study, RE inactivation does not always impair performance in hippocampal-dependent tasks (Loureiro et al., 2012). Indeed, a number of studies have observed spared retrieval of contextual fear memory after either muscimol (Holt and Maren, 1999; Maren and Holt, 2004; Matus-Amat et al., 2004; Sparks et al., 2011) or cobalt chloride (Resstel et al., 2008) infusions into the hippocampus, or optogenetic inhibition of dentate granule cells (Kheirbek et al., 2013; Bernier et al., 2017). Collectively, these data suggest that once contextual representations are learned (in an intact animal), they can be retrieved in the absence of the hippocampal system (Sparks et al., 2011).

The important role for $\mathrm{RE}$ in contextual fear conditioning is in line with previous work implicating the RE in HPC-dependent processes, such as spatial and working memory (Cassel and Pereira de Vasconcelos, 2015; Layfield et al., 2015; Hallock et al., 2016). In these tasks, memory relies heavily on contextual processing. During contextual fear conditioning, animals must encode a contextual representation that then comes into association with the aversive US. After acquisition, this memory yields conditioned freezing specific to the conditioning context and allows animals to discriminate the dangerous conditioning context from other, safe places. What might cause the contextual discrimination deficits observed after RE inactivation? One possibility is that animals without a functional RE use a nonhippocampal system to acquire an "elemental" representation of the context (Maren et al., 1997; Rudy and O’Reilly, 1999; Maren, 2001; Matus-Amat et al., 2004; Rudy and Matus-Amat, 2005). Bereft of a memory system that integrates multimodal sensory information into a unified, configural representation of context, animals with permanent damage to the RE might associate only the most salient features of the conditioning experience (perhaps even the experimenter or transport cues) with shock. These elemental associations would readily generalize across test contexts and fail to support subtle discriminations between contexts. Consistent with this view, many investigators have found that permanent hippocampal lesions fail to affect contextual conditioning per se (Maren et al., 1997; Frankland et al., 1998; Cho et al., 1999; Wiltgen et al., 2006), but impair contextual discrimination (Frankland et al., 1998; Cho et al., 1999).

Consistent with this proposition, we found that contextual memories acquired in animals after MUS infusions into the RE were not sensitive to intrahippocampal infusions of APV. In contrast, contextual conditioning was impaired by APV infusions into DH in animals trained after SAL infusions into the RE, consistent with many other reports (Stiedl et al., 2000; Quinn et al., 2005; Matus-Amat et al., 2007; Czerniawski et al., 2012). These results indicate that $\mathrm{RE}$ inactivation forces animals to acquire contextual fear memories in a hippocampal-independent manner, presumably through alternate neural systems that associate contextual elements with the US (Maren et al., 1997; Rudy and O’Reilly, 1999; Barrientos et al., 2002; Matus-Amat et al., 2004; Rudy and Matus-Amat, 2005). It is clear that the amygdala mediates pavlovian fear conditioning to both discrete and contextual CSs (Goosens and Maren, 2001; Maren, 2001; Wilensky et al., 2006), and it is likely that elements of the context (light, odor, or grid) are associated with the footshock US in the amygdala to support contextual conditioning in rats trained after RE inactivation. Previous studies have suggested that cortical regions such as prefrontal cortex, retrosplenial cortex, or perirhinal cortex can 
process contextual information independently of the hippocampus, and these regions may support context-US associations in the amygdala (Zelikowsky et al., 2013; Heroux et al., 2017; Coelho et al., 2018).

It has previously been argued that the hippocampal memory system functions to acquire configural representations of context that enable context conditioning and discrimination (Maren et al., 1997; Frankland et al., 1998; Rudy and O'Reilly, 1999; MatusAmat et al., 2004). Interestingly, in the absence of the hippocampal system, animals can acquire context memories using a nonhippocampal system that associates context elements with an aversive US to yield conditional freezing. However, this impoverished representation of context leads to considerable generalization, particularly across highly similar contexts. Under normal circumstances, hippocampal-dependent configural leaning overshadows the elemental learning system, which results in the encoding of context memories that later require the hippocampal system for retrieval (Sutherland et al., 2010; Sparks et al., 2011). In the context of the present results, this model suggests that the RE functions as a critical component of the hippocampal memory system involved in encoding precise contextual representations during fear conditioning. More specifically, our data reveal that (1) the RE functions to encode contextual memories that support contextual discriminations; and (2) when conditioning occurs during RE inactivation, memories of conditioning are formed, but are only accessible when retrieved again under RE inactivation. Interestingly, we also show that RE inactivation does not prevent the retrieval of contextual memories per se and causes inappropriate and generalized fear in safe contexts. Altogether, these results are consistent with the proposal that conditioned freezing to an aversive context can be supported by either a configural representation encoded by the hippocampal system or by an elemental representation encoded outside the hippocampus (Maren et al., 1997; Rudy and O'Reilly, 1999; Anagnostaras et al., 2001; Sparks et al., 2011; Chang and Liang, 2017). Configural representations normally overshadow the elemental representation of context to dominate performance during retrieval. Similar to hippocampal lesions, RE inactivation impairs configural encoding of context representations, rendering an elemental memory of the conditioning experience that is inhibited when the hippocampal system is active at the time of retrieval.

By this account, animals conditioned after RE inactivation encode an elemental representation of context (e.g., context $\mathrm{A}^{\prime}$ ) that comes into association with the US and is retrieved only when the animal encounters context $\mathrm{A}^{\prime}$ in the future. After fear conditioning, contextual freezing in animals conditioned under $\mathrm{RE}$ inactivation will be expressed only in context $\mathrm{A}^{\prime}$, which requires RE inactivation to be experienced. Moreover, this account assumes that configural representations of the context, which are encoded by the intact brain, are not only insufficient to retrieve the elemental $\mathrm{A}^{\prime}$ association, but in fact inhibit its retrieval. Ultimately, this leads to both deficits in the contextual freezing and poor contextual discrimination. Overall, the present data reveal that the RE is critical for contextual processes involved in fear conditioning and suggest that it is a critical hub for HPC-mPFC interactions involved in learning and memory.

\section{References}

Anagnostaras SG, Gale GD, Fanselow MS (2001) Hippocampus and contextual fear conditioning: recent controversies and advances. Hippocampus 11:8-17. CrossRef Medline

Barrientos RM, O'Reilly RC, Rudy JW (2002) Memory for context is impaired by injecting anisomycin into dorsal hippocampus following context exploration. Behav Brain Res 134:299-306. CrossRef Medline
Bernier BE, Lacagnina AF, Ayoub A, Shue F, Zemelman BV, Krasne FB, Drew MR (2017) Dentate gyrus contributes to retrieval as well as encoding: evidence from context fear conditioning, recall, and extinction. J Neurosci 37:6359-6371. CrossRef Medline

Cassel JC, Pereira de Vasconcelos A (2015) Importance of the ventral midline thalamus in driving hippocampal functions. Prog Brain Res 219:145161. CrossRef Medline

Chang SD, Liang KC (2017) The hippocampus integrates context and shock into a configural memory in contextual fear conditioning. Hippocampus 27:145-155. CrossRef Medline

Cho YH, Friedman E, Silva AJ (1999) Ibotenate lesions of the hippocampus impair spatial learning but not contextual fear conditioning in mice. Behav Brain Res 98:77-87. CrossRef Medline

Cholvin T, Loureiro M, Cassel R, Cosquer B, Geiger K, De Sa Nogueira D, Raingard H, Robelin L, Kelche C, Pereira de Vasconcelos A, Cassel JC (2013) The ventral midline thalamus contributes to strategy shifting in a memory task requiring both prefrontal cortical and hippocampal functions. J Neurosci 33:8772-8783. CrossRef Medline

Coelho CAO, Ferreira TL, Kramer-Soares JC, Sato JR, Oliveira MGM (2018) Network supporting contextual fear learning after dorsal hippocampal damage has increased dependence on retrosplenial cortex. PLoS Comput Biol 14:e1006207. CrossRef Medline

Czerniawski J, Ree F, Chia C, Otto T (2012) Dorsal versus ventral hippocampal contributions to trace and contextual conditioning: differential effects of regionally selective NMDA receptor antagonism on acquisition and expression. Hippocampus 22:1528-1539. CrossRef Medline

Davoodi FG, Motamedi F, Akbari E, Ghanbarian E, Jila B (2011) Effect of reversible inactivation of reuniens nucleus on memory processing in passive avoidance task. Behav Brain Res 221:1-6. CrossRef Medline

Frankland PW, Cestari V, Filipkowski RK, McDonald RJ, Silva AJ (1998) The dorsal hippocampus is essential for context discrimination but not for contextual conditioning. Behav Neurosci 112:863-874. CrossRef Medline

Goosens KA, Maren S (2001) Contextual and auditory fear conditioning are mediated by the lateral, basal, and central amygdaloid nuclei in rats. Learn Mem 8:148-155. CrossRef Medline

Goshen I, Brodsky M, Prakash R, Wallace J, Gradinaru V, Ramakrishnan C, Deisseroth K (2011) Dynamics of retrieval strategies for remote memories. Cell 147:678-689. CrossRef Medline

Griffin AL (2015) Role of the thalamic nucleus reuniens in mediating interactions between the hippocampus and medial prefrontal cortex during spatial working memory. Front Syst Neurosci 9:29. CrossRef Medline

Hallock HL, Wang A, Griffin AL (2016) Ventral midline thalamus is critical for hippocampal-prefrontal synchrony and spatial working memory. J Neurosci 36:8372-8389. CrossRef Medline

Hembrook JR, Mair RG (2011) Lesions of reuniens and rhomboid thalamic nuclei impair radial maze win-shift performance. Hippocampus 21:815826. CrossRef Medline

Hembrook JR, Onos KD, Mair RG (2012) Inactivation of ventral midline thalamus produces selective spatial delayed conditional discrimination impairment in the rat. Hippocampus 22:853-860. CrossRef Medline

Heroux NA, Robinson-Drummer PA, Sanders HR, Rosen JB, Stanton ME (2017) Differential involvement of the medial prefrontal cortex across variants of contextual fear conditioning. Learn Mem 24:322-330. CrossRef Medline

Holt W, Maren S (1999) Muscimol inactivation of the dorsal hippocampus impairs contextual retrieval of fear memory. J Neurosci 19:9054-9062. CrossRef Medline

Jin J, Maren S (2015a) Prefrontal-hippocampal interactions in memory and emotion. Front Syst Neurosci 9:170. CrossRef Medline

Jin J, Maren S (2015b) Fear renewal preferentially activates ventral hippocampal neurons projecting to both amygdala and prefrontal cortex in rats. Sci Rep 5:8388. CrossRef Medline

Kheirbek MA, Drew LJ, Burghardt NS, Costantini DO, Tannenholz L, Ahmari SE, Zeng H, Fenton AA, Hen R (2013) Differential control of learning and anxiety along the dorsoventral axis of the dentate gyrus. Neuron 77:955-968. CrossRef Medline

Layfield DM, Patel M, Hallock H, Griffin AL (2015) Inactivation of the nucleus reuniens/rhomboid causes a delay-dependent impairment of spatial working memory. Neurobiol Learn Mem 125:163-167. CrossRef Medline

Loureiro M, Cholvin T, Lopez J, Merienne N, Latreche A, Cosquer B, Geiger 
K, Kelche C, Cassel JC, Pereira de Vasconcelos A (2012) The ventral midline thalamus (reuniens and rhomboid nuclei) contributes to the persistence of spatial memory in rats. J Neurosci 32:9947-9959. CrossRef Medline

Marek R, Jin J, Goode TD, Giustino TF, Wang Q, Acca GM, Holehonnur R, Ploski JE, Fitzgerald PJ, Lynagh T, Lynch JW, Maren S, Sah P (2018) Hippocampus-driven feed-forward inhibition of the prefrontal cortex mediates relapse of extinguished fear. Nat Neurosci 21:384-392. CrossRef Medline

Maren S (2001) Neurobiology of pavlovian fear conditioning. Annu Rev Neurosci 24:897-931. CrossRef Medline

Maren S, Holt WG (2004) Hippocampus and pavlovian fear conditioning in rats: muscimol infusions into the ventral, but not dorsal, hippocampus impair the acquisition of conditional freezing to an auditory conditional stimulus. Behav Neurosci 118:97-110. CrossRef Medline

Maren S, Aharonov G, Fanselow MS (1997) Neurotoxic lesions of the dorsal hippocampus and pavlovian fear conditioning in rats. Behav Brain Res 88:261-274. CrossRef Medline

Matus-Amat P, Higgins EA, Barrientos RM, Rudy JW (2004) The role of the dorsal hippocampus in the acquisition and retrieval of context memory representations. J Neurosci 24:2431-2439. CrossRef Medline

Matus-Amat P, Higgins EA, Sprunger D, Wright-Hardesty K, Rudy JW (2007) The role of dorsal hippocampus and basolateral amygdala NMDA receptors in the acquisition and retrieval of context and contextual fear memories. Behav Neurosci 121:721-731. CrossRef Medline

McKenna JT, Vertes RP (2004) Afferent projections to nucleus reuniens of the thalamus. J Comp Neurol 480:115-142. CrossRef Medline

Orsini CA, Kim JH, Knapska E, Maren S (2011) Hippocampal and prefrontal projections to the basal amygdala mediate contextual regulation of fear after extinction. J Neurosci 31:17269-17277. CrossRef Medline

Preston AR, Eichenbaum H (2013) Interplay of hippocampus and prefrontal cortex in memory. Curr Biol 23:R764-R773. CrossRef Medline

Quinn JJ, Loya F, Ma QD, Fanselow MS (2005) Dorsal hippocampus NMDA receptors differentially mediate trace and contextual fear conditioning. Hippocampus 15:665-674. CrossRef Medline

Resstel LB, Joca SR, Corrêa FM, Guimarães FS (2008) Effects of reversible inactivation of the dorsal hippocampus on the behavioral and cardiovascular responses to an aversive conditioned context. Behav Pharmacol 19:137-144. CrossRef Medline

Rudy JW, Matus-Amat P (2005) The ventral hippocampus supports a memory representation of context and contextual fear conditioning: implications for a unitary function of the hippocampus. Behav Neurosci 119: 154-163. CrossRef Medline
Rudy JW, O'Reilly RC (1999) Contextual fear conditioning, conjunctive representations, pattern completion, and the hippocampus. Behav Neurosci 113:867-880. CrossRef Medline

Schlichting ML, Preston AR (2016) Hippocampal-medial prefrontal circuit supports memory updating during learning and post-encoding rest. Neurobiol Learn Mem 134:91-106. CrossRef Medline

Sparks FT, Lehmann H, Sutherland RJ (2011) Between-systems memory interference during retrieval. Eur J Neurosci 34:780-786. CrossRef Medline

Stiedl O, Birkenfeld K, Palve M, Spiess J (2000) Impairment of conditioned contextual fear of C57BL/6J mice by intracerebral injections of the NMDA receptor antagonist APV. Behav Brain Res 116:157-168. CrossRef Medline

Sutherland RJ, Sparks FT, Lehmann H (2010) Hippocampus and retrograde amnesia in the rat model: a modest proposal for the situation of systems consolidation. Neuropsychologia 48:2357-2369. CrossRef Medline

Troyner F, Bicca MA, Bertoglio LJ (2018) Nucleus reuniens of the thalamus controls fear memory intensity, specificity and long-term maintenance during consolidation. Hippocampus 28:602-616. CrossRef Medline

Vertes RP, Hoover WB, Do Valle AC, Sherman A, Rodriguez JJ (2006) Efferent projections of reuniens and rhomboid nuclei of the thalamus in the rat. J Comp Neurol 499:768-796. CrossRef Medline

Vetere G, Kenney JW, Tran LM, Xia F, Steadman PE, Parkinson J, Josselyn SA, Frankland PW (2017) Chemogenetic interrogation of a brain-wide fear memory network in mice. Neuron 94:363-374.e4. CrossRef Medline

Wang Q, Jin J, Maren S (2016) Renewal of extinguished fear activates ventral hippocampal neurons projecting to the prelimbic and infralimbic cortices in rats. Neurobiol Learn Mem 134:38-43. CrossRef Medline

Wilensky AE, Schafe GE, Kristensen MP, LeDoux JE (2006) Rethinking the fear circuit: the central nucleus of the amygdala is required for the acquisition, consolidation, and expression of pavlovian fear conditioning. J Neurosci 26:12387-12396. CrossRef Medline

Wiltgen BJ, Sanders MJ, Anagnostaras SG, Sage JR, Fanselow MS (2006) Context fear learning in the absence of the hippocampus. J Neurosci 26:5484-5491. CrossRef Medline

Xu W, Südhof TC (2013) A neural circuit for memory specificity and generalization. Science 339:1290-1295. CrossRef Medline

Zelikowsky M, Bissiere S, Hast TA, Bennett RZ, Abdipranoto A, Vissel B, Fanselow MS (2013) Prefrontal microcircuit underlies contextual learning after hippocampal loss. Proc Natl Acad Sci U S A 110:9938-9943. CrossRef Medline 